\title{
Estimating Aircraft Landing Weights from Mode S Data
}

\author{
Frank Holzäpfel*, Grigory Rotshteyn \\ Deutsches Zentrum für Luft- und Raumfahrt, Institut für Physik der Atmosphäre, \\ 82234 Oberpfaffenhofen, Germany
}

\begin{abstract}
Aircraft weights prior to touchdown are assessed employing equations suggested for estimates of descent speeds depending on aircraft gross mass following BADA (Base of Aircraft Data). The required aircraft type, calibrated airspeed and air density data are derived from Mode S data protocols. Landing weights of 3328 aircraft approaching Vienna airport, provided by Austrian Airlines, serve as reference gross masses. Average aircraft masses during final approach vary between $85 \%$ and $93 \%$ of the maximum landing weight depending on the aircraft type. A simple correction for the observed inclination of pilots to fly somewhat faster than prescribed in reference handbooks eliminates the bias of the mass estimates in the current data base, while the respective standard deviation amounts to approximately $5 \%$.
\end{abstract}

\section{Introduction}

$\mathrm{A}$ IRCRAFT mass is a key parameter controlling aircraft performance and thus the prediction of aircraft path routings, climb and descent profiles and hence also constitutes relevant information for aircraft traffic management. However, this proprietary data is usually not easily accessible, because airlines consider it confidential information.

During the definition process of the concepts of operations (OSED) for transmitting aircraft-derived meteorological data to enable a wide range of Next Generation Air Transportation System (NextGen) and Single European Sky ATM Research (SESAR) applications in the areas of wake turbulence, air traffic management, and meteorology, it was generally agreed that aircraft mass should be incorporated into the downlink and crosslink of aircraft-derived data ${ }^{1,2}$. However, it was also stated that aircraft mass is traditionally considered sensitive information due to operator concerns about potentially releasing data to competitors ${ }^{2}$. This classification may continue to hamper the provision of mass data in future data protocols.

As wake turbulence constitutes a potential risk for following aircraft, separation standards between consecutive aircraft have been established that limit the capacity of congested airports ${ }^{3}$. Because the strength of aircraft wake vortices is directly proportional to the aircraft weight ${ }^{4}$, mass information is required for the prediction of pairwise dynamic aircraft separations for approach and landing with a wake vortex advisory system ${ }^{5}$. Here the consideration of landing weight extends from the operational empty weight to the maximum landing weight, leading to wide ranges of initial wake vortex strength which in turn are limiting the potential capacity gains of such advisory systems ${ }^{6,7}$. For efficient onboard prediction of wake turbulence, the wake vortex volumes that need to be avoided by other aircraft should be as compact as possible. To accomplish this objective, the knowledge of aircraft mass is of paramount importance $^{8}$. Also, the RECAT process for the optimization of wake turbulence separations initiated by ICAO, requires adequate landing weights for the classification into different categories ${ }^{9,10}$. The estimation of runway occupancy times, another important element for optimizing arrival capacity of busy airports, also depends on reliable

\footnotetext{
* Senior Scientist, frank.holzaepfel@dlr.de, Associate Fellow AIAA
} 
estimates of aircraft landing weights. Moreover, the planning of continuous descent operations or adaptive increased glide slopes aiming at reduced fuel consumption and noise mitigation depend on the aircraft gross mass ${ }^{11,12}$.

A number of partly quite extensive methods for the estimation of aircraft weights have been reported in literature. Alligier et al. focus on the estimation of aircraft mass during the climb phase using point-mass model parameters from observations fitting the modeled power to the observed energy rate ${ }^{13,14}$. Sun et al. estimate take-of mass from total energy model estimates at different flight phases where validation experiments yield a mean absolute error of $4.3 \%$ of the actual aircraft mass ${ }^{15}$. Fricke et al. present a technique to estimate the aircraft gross mass for calculating the optimum rate of descent employing a flight mechanical approach using the measured approach ground speed ${ }^{11}$. The validation based on 12 flight trajectories yields an average deviation between modeled and recorded gross mass of $12.3 \%$. Measurements of actual landing weights at the airports Memphis and Dallas/Fort Worth resulted in an overall average of $85 \%$ of the maximum landing weight $(\mathrm{MLW})^{16}$. This average value was also adopted as typical landing weight in the European Proposal for revised Wake Turbulence Categorisation and Separation Minima on Approach and Departure (RECAT-EU) ${ }^{17}$.

This note employs equations suggested for estimates of descent speeds depending on aircraft gross mass following BADA $^{18}$ (Base of Aircraft Data) to estimate aircraft weights prior to touchdown. The required aircraft type, calibrated airspeed and air density data are derived from Mode S data protocols. Landing weights of 3328 aircraft approaching Vienna airport, provided by Austrian Airlines for the analysis of the wake turbulence mitigation field measurement campaign ${ }^{19,20}$ conducted from May to November 2019, serve as reference masses. A simple correction for the observed inclination of pilots to fly somewhat faster than prescribed in reference handbooks eliminates the bias of the mass estimates in the current data base.

\section{Method}

\section{A. Mode-S-Based Mass Estimates}

At Vienna International Airport a measurement campaign has been accomplished from 6 May 2019 until 28 November 2019 in order to assess the potential of so-called plate lines to mitigate wake turbulence risks during final approach ${ }^{19,20}$. The wake vortex measurements employing three lidars (light detection and ranging) were conducted in five measurement planes in which the flight altitudes above ground were determined from Mode $\mathrm{S}$ data to $40.8 \mathrm{~m}, 45.8 \mathrm{~m}, 54.3 \mathrm{~m}, 64.8 \mathrm{~m}$, and $74.5 \mathrm{~m}$, respectively, with a standard deviation of $4.9 \mathrm{~m}$. The mass estimates, derived from Mode $\mathrm{S}$ data interpolated to these five measurement planes, are all adopted in the statistics in order to smoothen the scatter caused by intended airspeed variations and those introduced by turbulence as well as random measurement error.

Mode $\mathrm{S}$ is a secondary surveillance radar process that allows selective interrogation of aircraft employing groundbased interrogators and airborne transponders ${ }^{21}$. The provided Mode $S$ data protocols contain date, time, aircraft position, attitude, and airspeed data as well as atmospheric pressure, wind speed and temperature data at an update rate of four seconds. Meta-data in the file for each landing provides the aircraft type, callsign, origin, destination, timestamps for the start and end of aircraft tracking, as well as the runway intended for landing. From these available parameters the determination of aircraft gross mass employs the aircraft type and the values of true airspeed, air pressure, and temperature.

According to BADA ${ }^{18}$ calibrated airspeeds, $V_{C A S}$, for jet and turboprop aircraft in the descent phase amount to

$$
V_{C A S}=C_{V \min } \cdot V_{\text {stall }}+V d_{D E S}
$$

where $C_{V \min }=1.3$ and $V_{\text {stall }}$ is the stall speed for the landing configuration of the particular aircraft type. The descent speed increment $V d_{D E S}$ amounts to 5 knots for flight altitudes below $1000 \mathrm{ft}$, to 10 knots between $1000 \mathrm{ft}$ and $1500 \mathrm{ft}$, to 20 knots between $1500 \mathrm{ft}$ and $2000 \mathrm{ft}$, and to 50 knots between $2000 \mathrm{ft}$ and $3000 \mathrm{ft}$. Aircraft operating speeds vary with the aircraft mass. This variation is considered according to

$$
V_{\text {stall }}=V_{\text {stall, }, \text { ref }} \cdot \sqrt{\frac{m}{m_{\text {ref }}}}
$$

American Institute of Aeronautics and Astronautics 
where $V_{\text {stall,ref }}$ is the reference stall speed for the landing configuration of the particular aircraft type and $m_{\text {ref }}$ its respective reference mass. From equations (1) and (2) the landing mass can be estimated according to

$$
m=\left(\frac{V_{C A S}-V d_{D E S}}{C_{V \min } \cdot V_{\text {stall,ref }}}\right)^{2} m_{r e f}
$$

The true airspeed, $V_{T A S}$, from the Mode $\mathrm{S}$ protocol is translated into calibrated airspeed, $V_{C A S}$, with the relation

$$
V_{C A S}=V_{T A S} \sqrt{\rho / \rho_{0}}
$$

simplified for low flight altitudes, where $\rho_{0}$ is the density of air at sea level of the International Standard Atmosphere. Air density $\rho$ is retrieved from pressure, $p$, and temperature, $T$, employing the equation of state for perfect gases $\rho=p / R T$, where the gas constant amounts to $R=287 \mathrm{~J} / \mathrm{kg} \mathrm{K}$ for dry air. More elaborate computations of $V_{C A S}$ from $V_{T A S}$ (see BADA user manual ${ }^{18}$ ) on average increased the landing mass estimates by only $0.027 \%$ and are therefore not considered here.

\section{B. Reference Mass Data}

Austrian Airlines kindly provided the landing weight, $m$, of all recorded landings of their fleet during the Vienna field trial. The weight data was provided for 2958 landings of the A320 family representative of the ICAO weight category Medium and category D "Upper Medium" of the RECAT-EU scheme. The landings of the A320 family comprise 560 A319 aircraft, 1932 A320 aircraft, and 466 A321 aircraft. Landings of the B767300ER falling into category C "Lower Heavy" of the RECAT-EU scheme amount to 225. The B777-200ER with 145 landings is the most frequent representative of the RECAT-EU scheme B "Upper Heavy" within the Vienna data base (1.2\% traffic share).

These weights serve as a reference to assess the weight estimates derived from Mode $\mathrm{S}$ data. The reference landing weights are quoted from the estimated initial aircraft weight and its fuel consumption. Prior to every flight a load and balance sheet is established, where the load sheet contains the planned take-off mass. After the flight the fuel consumption corrected by the consumption for the taxiing to and from the runway is subtracted from the take-off mass. The fuel consumption is captured by flow rate measuring devices located directly at the jet engines and is displayed in the cockpit where the display is set at zero with every engine start.

\section{Statistical Analyses}

Table 1 presents landing weight statistics of the considered aircraft types. While the average mass of the B767300ER almost perfectly coincides with the $85 \%$ of the MLW found in the statistics collected at Memphis and Dallas/Fort Worth airports ${ }^{16}$, the other aircraft types are heavier than $85 \%$ of the MLW by 6.9 (B777) and 7.8 (A320) percentage points. The respective standard deviations, $\sigma(\mathrm{LW} / \mathrm{MLW})$, varying between $2.7 \%$ and $5.4 \%$ appear relatively small.

Table 1 Landing weight statistics.

\begin{tabular}{cccc}
\hline \hline & landings & LW/MLW & $\sigma($ LW/MLW $)$ \\
\hline A320 family & 2958 & $92.8 \%$ & $5.4 \%$ \\
B767-300ER & 225 & $84.9 \%$ & $2.7 \%$ \\
B777-200ER & 145 & $91.9 \%$ & $3.6 \%$ \\
\hline \hline
\end{tabular}

American Institute of Aeronautics and Astronautics 
Figure 1 depicts the landing weights estimated according to equations (3) and (4) from Mode S data plotted against the reference masses provided by Austrian Airlines. To avoid unrealistically high landing masses the estimated masses were alternatively clipped off at the MLW (black dots) or at 95\% of the MLW (blue dots). The clusters representing the A320 family (bottom left), the B767-300ER (center), and the B777-200ER aircraft (top right) are clearly delimited. The data from the five measurement planes for one landing aircraft frequently appear as five vertically aligned data points, because any speed variation of the aircraft while passing the five measurement planes corresponds to mass estimate variations, while the reference data only provides one mass value for each landing aircraft. This effect is most apparent with the few outliers of the B777-200ER weight estimates. Obviously, the aircraft weights are overestimated for all aircraft types while the scatter of the mass data is reasonably low.

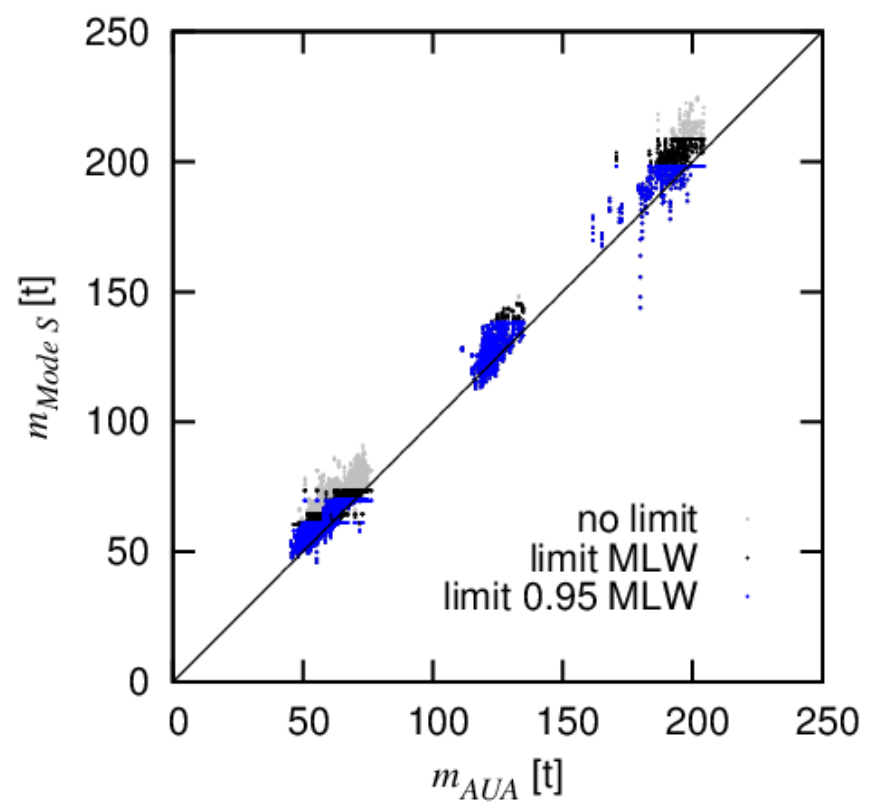

Figure 1 Estimated landing weights partly clipped off at different fractions of the MLW against actual weights of several aircraft types.

Table 2 lists the corresponding biases and standard deviations between estimated and reference landing weights of the data plotted in Figure 1 without clipping. The A320 family features the largest relative weight overestimates and corresponding standard deviations whereas the B767-300ER data shows the smallest deviations.

Table 2 Deviations between estimated and actual landing weights (not clipped).

\begin{tabular}{lccc}
\hline \hline & landings & bias & $\sigma$ \\
\hline A320 family & 2958 & $8.6 \%$ & $5.1 \%$ \\
B767-300ER & 225 & $3.8 \%$ & $3.7 \%$ \\
B777-200ER & 145 & $4.6 \%$ & $3.6 \%$ \\
\hline \hline
\end{tabular}

The exclusion of estimated weights above the MLW reduces the bias and the standard deviation mostly for the A320 family (Table 3). As the A320 family exhibits both the highest relative landing weights (see Table 1) and the highest mass overestimates (Table 2), the relative frequency of landings with clipped off masses is also the highest. For the B767-300ER with an average landing weight of 0.85 MLW, the MLWs are almost not exceeded by the estimates such that the figures are almost unchanged compared to Table 2.

American Institute of Aeronautics and Astronautics 
Table 3 Deviations between estimated and actual landing weights (clipped at 100\% MLW).

\begin{tabular}{ccccc}
\hline \hline & landings & clipped & bias & $\sigma$ \\
\hline A320 family & 2958 & 1778 & $5.3 \%$ & $3.9 \%$ \\
B767-300ER & 225 & 2 & $3.8 \%$ & $3.6 \%$ \\
B777-200ER & 145 & 30 & $4.1 \%$ & $3.2 \%$ \\
\hline \hline
\end{tabular}

Clipping estimated masses above 0.95 MLW reduces the bias for all aircraft types with little impact on the standard deviations. As can be seen in Figure 1 the clipping partly compensates the overestimates of the Mode S data approach such that the biases are reduced.

Table 4 Deviations between estimated and actual landing weights (clipped at 95\% MLW).

\begin{tabular}{lcccc}
\hline \hline & landings & clipped & bias & $\sigma$ \\
\hline A320 family & 2958 & 2414 & $1.6 \%$ & $4.7 \%$ \\
B767-300ER & 225 & 20 & $3.6 \%$ & $3.4 \%$ \\
B777-200ER & 145 & 99 & $2.0 \%$ & $3.2 \%$ \\
\hline \hline
\end{tabular}

Typical landing speeds are slightly higher than quoted in reference handbooks to have at command a certain buffer for unforeseen events, such as rapid changes in wind speed or direction. A comparison of the measured approach speeds with those prescribed for landing in the A320 Quick Reference Handbook indicates that A320 pilots fly on average by $1.2 \mathrm{~m} / \mathrm{s}$ faster than scheduled. This comparison considers the aircraft gross mass and headwind strength and assumes that the pilots employed the landing configuration full and activated the autothrust system.

Figure 2 exhibits that a doubling of the descent speed increment $V d_{D E S}$ to 10 knots reduces the mass estimates substantially. As a consequence, the bias for all aircraft types almost completely vanishes as detailed in Table 5, whereas the standard deviation remains almost the same. Figure 2 further indicates that the doubling of $V d_{D E S}$ appears slightly overdone for the Boeing aircraft and slightly underrated for Airbus aircraft.

Figure 3 delineates the distribution of the relative differences between the estimated landing masses with $V d_{D E S}=10$ knots and the reference masses. Unsurprisingly, the distribution is skewed with a steeper decline towards the MLW.

American Institute of Aeronautics and Astronautics 


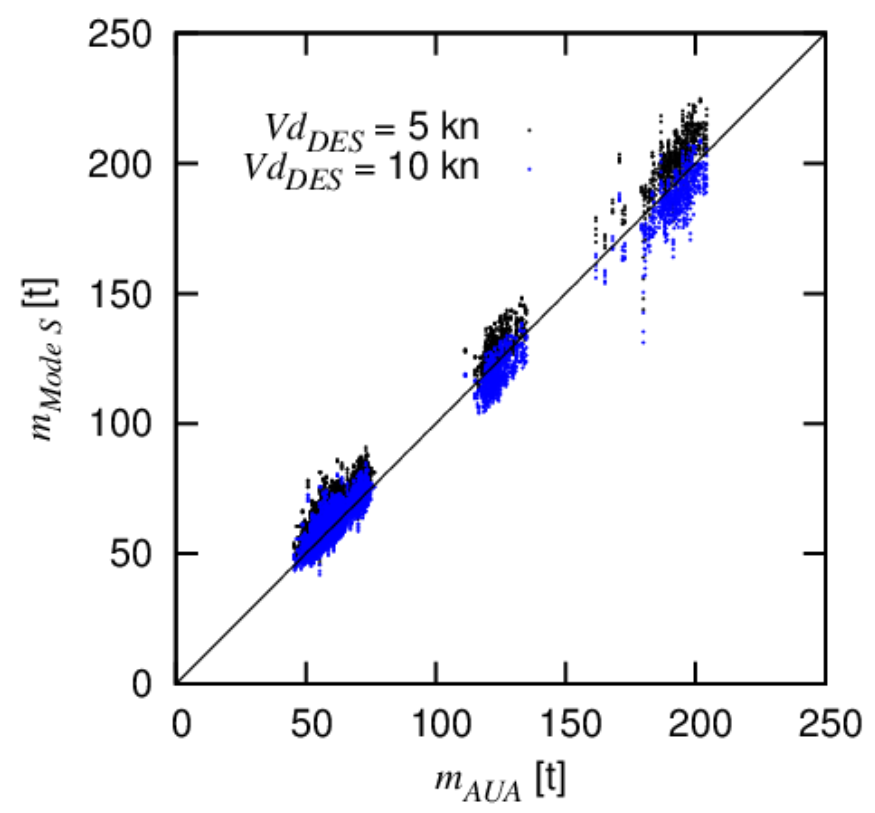

Figure 2 Estimated and actual landing weights for different values of $V d_{D E S}$ and several aircraft types.

Table 5 Deviations between estimated and actual landing weights varying $V d_{D E S}$.

\begin{tabular}{ccccc}
\hline \hline & $V d_{D E S}$ & landings & bias & $\sigma$ \\
\hline \multirow{2}{*}{ all aircraft } & 5 knots & 3328 & $8.1 \%$ & $5.2 \%$ \\
& 10 knots & 3328 & $0.3 \%$ & $5.3 \%$ \\
\hline \hline
\end{tabular}

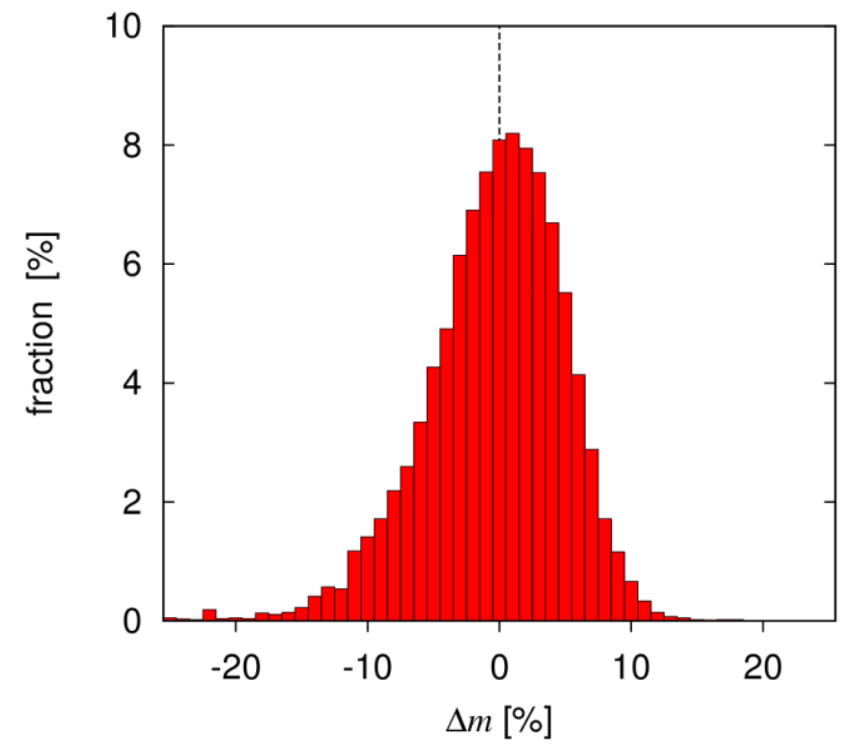

Figure 3 Distribution of relative differences between estimated and measured masses for all considered aircraft types with a doubling of $V d_{D E S}$. 
Finally, all Mode S data available during the descent from $3000 \mathrm{ft}$ to touchdown are used to assess the suitability of the mass estimates at higher altitudes employing the values for $V d_{D E S}$ introduced in section II.A. For this purpose, the deceleration of the aircraft within a height range was considered by linear interpolation of $V d_{D E S}$ leading to a somewhat reduced bias without much impact on the standard deviation. It was found that the standard deviation in the height range from 0 to $1000 \mathrm{ft}$ amounts to $6.7 \%$. The standard deviations are roughly doubled in the height range $1000 \mathrm{ft}$ to $1500 \mathrm{ft}$ to $12.7 \%$, tripled in the range $1500 \mathrm{ft}$ to $2000 \mathrm{ft}$ to $18.9 \%$, and increased fourfold between $2000 \mathrm{ft}$ and $3000 \mathrm{ft}$ to $27.4 \%$. Obviously, in the higher altitude ranges above $1000 \mathrm{ft}$ the standard deviations increase substantially, presumably because air traffic control prescribes the descent speeds depending on the wind and traffic situation. Already a doubling of the standard deviation limits the application of the weight estimate substantially for many purposes.

\section{Conclusion}

Aircraft landing weights are estimated from Mode S protocol data comprising the aircraft type and the values of true airspeed, air pressure, and temperature. These parameters are translated into air density and calibrated airspeed from which aircraft mass can be deduced employing reference stall speed and reference mass of the particular aircraft type obtained from the BADA database. The weight estimates are compared to reference data provided by Austrian Airlines for 3328 landings of the A320 family, the B767-300ER, and the B777-200ER. The agreement between the estimated and actual landing weights achieved with the unmodified approach is fair and the scatter of the mass data is reasonably low. The bias of the weight estimates can be reduced by clipping off overestimated weights exceeding the maximum landing weight (MLW) or $95 \%$ of the MLW. The gross mass bias can be almost completely eliminated by consideration of the tendency of pilots to slightly exceed the prescribed approach speeds. At flight heights above $1000 \mathrm{ft}$, the scatter of the mass estimates increases substantially, because actually flown airspeeds deviate increasingly with height from the average values assumed in the BADA database.

\section{Acknowledgments}

This project has received funding within the framework of the SESAR Joint Undertaking "Increased Runway and Airport Throughput" project (PJ.02 EARTH) and the "Safely Optimized Runway Throughput" project (VLD3-W2 SORT) within the European Union's Horizon 2020 research and innovation programme under grant agreement Nos 731781 and 874520 as well as from the German Aerospace Center (DLR) project "Wetter und disruptive Ereignisse". The provision of landing masses by W. Wurzinger from Austrian Airlines is greatly acknowledged and the provision of the Mode S data by L. Strauss and C. Weiß from MeteoServe Wetterdienst GmbH is highly appreciated. Finally, we give thanks to D. Vechtel from DLR Institut für Flugsystemtechnik for the instructive discussions.

\section{References}

\footnotetext{
${ }^{1}$ RTCA Inc., "Aircraft Derived Meteorological Data via Data Link for Wake Vortex, Air Traffic Management and Weather Applications, Operational Services and Environemntal Definition (OSED)”, RTCA DO-339, June 2012, 92 pages.

${ }^{2}$ RTCA Inc., "Standards Development Activities for using Near-Real-Time Aircraft-Derived Data in future applications," RTCA DO-360, September 2015, 62 pages.

${ }^{3}$ Hallock, J.N., Holzäpfel, F., "A Review of Recent Wake Vortex Research for Increasing Airport Capacity”, Progress in Aerospace Sciences, Vol. 98, 2018, pp. 27-36, https://doi.org/10.1016/j.paerosci.2018.03.003.

${ }^{4}$ Gerz, T., Holzäpfel, F., Darracq, D., “Commercial aircraft wake vortices,” Progress in Aerospace Sciences, Vol. 38, 2002, pp. 181-208, https://doi.org/10.1016/S0376-0421(02)00004-0.

${ }^{5}$ Holzäpfel, F., Strauss, L., Schwarz, C., "Assessment of Dynamic Pairwise Wake Vortex Separations for Approach and Landing at Vienna Airport,” Aerospace Science and Technology, Vol. 112, 2021, pp. 106618, https://doi.org/10.1016/j.ast.2021.106618.

${ }^{6}$ Holzäpfel, F., Gerz, T., Frech, M., Tafferner, A., Köpp, F., Smalikho, I., Rahm, S., Hahn, K.-U., Schwarz, C., "The Wake Vortex Prediction and Monitoring System WSVBS Part I: Design," Air Traffic Control Quarterly, Vol. 17, No. 4, 2009, pp. 301-322, https://doi.org/10.2514/atcq.17.4.301.
}

American Institute of Aeronautics and Astronautics 
${ }^{7}$ T. Gerz, F. Holzäpfel, W. Gerling, A. Scharnweber, M. Frech, K. Kober, K. Dengler, S. Rahm, The Wake Vortex Prediction and Monitoring System WSVBS Part II: Performance and ATC Integration at Frankfurt Airport, Air Traffic Control Quarterly, Vol. 17, No. 4, 2009, pp. 323-346, https://doi.org/10.2514/atcq.17.4.323.

${ }^{8}$ Sölch, I., Holzäpfel, F., Abdelmoula, F., Vechtel, D., "Performance of on-board wake vortex prediction systems employing various meteorological data sources", Journal of Aircraft, Vol. 53, Issue 5, pp. 1505-1516, 2016, DOI: : http://arc.aiaa.org/doi/abs/10.2514/1.C033732.

${ }^{9}$ Cheng, J., Tittsworth, J., Gallo, W., Awwad, A., "The Development of Wake Turbulence Recategorization in the United States, AIAA Paper 2016-3434, June 2016, p. 12.

${ }^{10}$ RECAT-EU, European Wake Turbulence Categorisation and Separation Minima on Approach and Departure, EUROCONTROL, 2015, p. 32, https://www.eurocontrol.int/publication/european-wake-turbulence-categorisation-and-separation-minima-approach-and-departure, (Accessed 12 March 2021)

${ }^{11}$ Fricke, H., Seiß, C., Herrmann, R., "Fuel and energy benchmark analysis of continuous descent operations," Air Traffic Control Quarterly, Vol. 23, No. 1, 2015, pp. 83-108, https://doi.org/10.2514/atcq.23.1.83.

${ }^{12}$ Clarke, J.-P. B., Ho, N. T., Ren, L., Brown, J. A., Elmer, K. R., Tong, K.-O., Wat, J. K., "Continuous Descent Approach: Design and Flight Test for Louisville International Airport", Journal of Aircraft, Vol. 41, Issue 5, pp. 1054-1066, 2004, https://doi.org/10.2514/1.5572.

${ }^{13}$ Alligier, R., Gianazza, D., Durand, N., "Learning the aircraft mass and thrust to improve the ground-based trajectory prediction of climbing flights," Transportation Research Part C: Emerging Technologies, Vol. 36, 2013, pp. 45-60, https://doi.org/10.1016/j.trc.2013.08.006.

${ }^{14}$ Alligier, R., Gianazza, D., Ghasemi Hamed, M., Durand, N., "Comparison of Two Ground-based Mass Estimation Methods on Real Data," International Conference on Research in Air Transportation (ICRAT), Istanbul, Turkey, May 2014, 8 pages, http://www.icrat.org.

${ }^{15}$ Sun, J., Ellerbroek, J., and Hoekstra, J. "Aircraft initial mass estimation using Bayesian inference method". In: Transportation Research Part C: Emerging Technologies 90 (2018), pp. 59-73, https://doi.org/10.1016/j.trc.2018.02.022.

${ }^{16}$ Delisi, Donald P., Matthew J. Pruis, Frank Y. Wang, David Y. Lai, Estimates of the Initial Vortex Separation Distance, bo, of Commercial Aircraft from Pulsed Lidar Data, AIAA Paper 2013-0365, 51st AIAA Aerospace Sciences Meeting including the New Horizons Forum and Aerospace Exposition, 07 - 10 January 2013, Grapevine (Dallas/Ft. Worth Region), Texas, 2013, 10 pages.

${ }^{17}$ EUROCONTROL, European Proposal for revised Wake Turbulence Categorisation and Separation Minima on Approach and Departure "RECAT - EU" - Safety Case Report, 2017, 234 pages.

${ }^{18}$ BADA, User Manual for the Base of Aircraft Data (BADA) Revision 3.11, EEC Technical/Scientific Report No. 13/04/16-01, EUROCONTROL, May 2013, 109 pages. http://upcommons.upc.edu/bitstream/handle/2099.1/24342/AnnexI.pdf?sequence=2. (Accessed 12 March 2021)

${ }^{19}$ Holzäpfel, F., Stephan, A., Rotshteyn, G., Körner, S., Wildmann, N., Oswald, L., Gerz, T., Borek, G., Floh, A., Kern, C., Kerschbaum, M., Nossal, R., Schwarzenbacher, J., Stieber, M., Strobel, M., Strauss, L., Weiß, C., Kauczok, S., Schiefer, C., Czekala, H., Maschwitz, G., Smalikho, I., "Mitigating Wake Turbulence Risk During Final Approach via Plate Lines," AIAA Paper 2020-2835, AIAA Aviation 2020 Forum, June 2020, 24 pages, https://doi.org/10.2514/6.2020-2835.

${ }^{20}$ Holzäpfel, F., Stephan, A., Rotshteyn, G., Körner, S., Wildmann, N., Oswald, L., Gerz, T., Borek, G., Floh, A., Kern, C., Kerschbaum, M., Nossal, R., Schwarzenbacher, M., Strobel, M., Strauss, L., Weiß, C., Kauczok, S., Schiefer, C., Czekala, H., Maschwitz, G., Smalikho, I., "Mitigating Wake Turbulence Risk During Final Approach via Plate Lines," AIAA Journal, accepted for publication, https://doi.org/10.2514/1.J060025.

${ }^{21}$ ICAO, Manual on Mode S Specific Services, Doc 9688, AN/952, $2^{\text {nd }}$ Edition, 2004, http://www.anteni.net/adsb/Doc/9688 cons en.pdf. (Accessed 12 March 2021)

American Institute of Aeronautics and Astronautics 